Research, part of a Special Feature on Vulnerability and Adaptation to Oil Spills

\title{
After the Cap: Risk Assessment, Citizen Science and Disaster Recovery
}

\author{
Sabrina McCormick ${ }^{1}$
}

\begin{abstract}
I used the 2010 Deepwater Horizon oil spill to examine how crowdsourcing is used as a new form of citizen science that provides real time assessments of health-related exposures. Assessing risks of an oil spill, or disasters more generally, is a challenge complicated by the situated nature of knowledge-generation that results in differential perceptions and responses. These processes are critical in the case of the British Petroleum spill in the Gulf Coast since the identification of risks promises to have ramifications for multiple social actors, as well as the health status and long-term resilience of communities in the area. Qualitative interviews, ethnographic observations, and video data were collected with local social movement organizations, grassroots groups, spill workers, fisherman, local residents, scientists, and government representatives within five months of the spill. Findings suggest that crowdsourcing is a new form of citizen science reflecting a transition from lay mapping to an online data gathering system that allows a broader range of participation and the detection of a broader range of impacts. Outcomes of this research promise to help demonstrate and theorize how citizen science relates to risk assessment processes and affects disaster recovery and long-term response.
\end{abstract}

Key Words: Deepwater Horizon; citizen science; health; oil spill

\section{INTRODUCTION}

Through study of the 2010 Deepwater Horizon oil spill we can examine how crowdsourcing is used as a new form of citizen science that provides real time assessments of health-related exposures. A crowdsourcing system enlists a crowd of humans to help solve a problem defined by system owners (Dan et al. 2011). It is based on the ability of a large group of people to naturally recognize patterns, often in a local, immediate way that is more accurate than individuals recollecting the past, and more precise than judging impacts from a distance. Human health impacts, in particular, are identified through local citizen science wherein lay people engage in research design, data collection, and analysis (Trumbull et al. 2000), and whose endeavors focus on embodied and experiential dimensions. Citizen science can more accurately describe health effects and potential community-level responses to disasters and this oil spill since it may provide a more immediate, fine grain, localized assessment.

While there is a rich literature on the role of citizen science in detecting environmental exposures otherwise undetected by experts due to lack of awareness, lack of sufficient methods for exposure identification, or other limitations to science, little work has focused on how this takes place in disaster settings or the new technological tools used by social movements and communities. This article suggests that crowdsourcing is a new form of citizen science that reflects a transition from lay mapping, which has been a common tactic in the environmental movement for over two decades, to an online data gathering system that allows a broader range of participation and, potentially, the detection of a broader range of impacts. It additionally suggests that this form of citizen science can offer increased legitimacy for activist claims in government policy.

\section{SCIENTIFIC CONTROVERSIES OF OIL SPILL OUTCOMES}

The Deepwater Horizon spill occurred on April 20, 2010, resulting in the largest single oil spill in the history of the United States and engendering critical debates about its impacts. Almost five million barrels of oil were released into the Gulf of Mexico before the rig was capped (Hoch 2010). Over 2.1 million gallons of Corexit, a chemical dispersant, were then applied, even though the Environmental Protection Agency (EPA) requested that British Petroleum (BP), who was in control of spill clean-up, use a less toxic alternative (Kujawinksi et al. 2011). Fish and wildlife populations experienced massive impacts from both the oil and the dispersant as birds, dolphins, and fish populations died across the Gulf region. Real time monitoring of exposures to the spill and its observable impacts quickly became a question debated by government representatives, BP officials, local communities, and oil spill workers. Without these data, drawing a cause-effect link between the spill and long-term outcomes is difficult. Yet, the long-term impacts of the Gulf Oil Spill are potentially wide-ranging, legally-charged, and economically impactful.

Concerns about the most effective approach for identifying real time exposures and resultant oil spill impacts have been raised due to past challenges to detecting health and environmental impacts. Lack of data has plagued efforts to establish long-term outcomes, resulting in prolonged legal battles and dissatisfied communities (Paine et al. 1996, Golet et al. 2002). Some of the strongest research on impacts has shown the mental health effects of oil spills, such as depression, anxiety, and Post Traumatic Stress Disorder (Palinkas et al. 1993a, Arata et al. 2000, Sabucedo 2010). For example, the Exxon Valdez oil spill directly affected the social 
structure of the Cordova, Alaska community by disrupting commercial fishing harvests (Picou et al. 2004).

Past disagreements over the impacts of oil spills raise questions about the conflation of citizen concerns, risk perception, and identification of effects. This is further suggested by studies that show no cytotoxic effects from exposure to oil spills (Forbes 1994). Yet, studies, such as on the Sea Empress oil spill, show a significant increase in self-reported headaches, sore eyes, and sore throat (Lyons 1999). In that case, risk perception did not bias outcomes as the belief that oil had affected health was adjusted for in the analysis. Additionally, among clean-up crews working during the Nakhodka oil spill, longer working days were associated with increases in complaints of symptoms, different kinds of symptoms, and duration of symptoms (Morita 1998). Further research has shown that a range of exposures have been neglected by experts in past oil spills, including those to communities, workers, and the environment (Morita et al. 1999, Ha et al. 2008). Clean-up workers who face immediate and long-term risks are particularly vulnerable to such oversight. Exposures in the workplace are often some of the most potent environmental health risks. Such marginalization of worker concerns has occurred in the process of avoiding legal ramifications for minimal worker protections and inadequate measurement of exposures (Markowitz and Rosner 2003).

\section{THE ORIGINS OF CITIZEN SCIENCE IN THE GULF}

Citizen science has emerged to play a new role in the detection of oil spill impacts. Citizen science efforts in the Gulf were meant to address similar questions about how exposures from the spill would affect communities. Since the inception of the spill, local nongovernmental organizations have been involved in assessing the exposures to and risks from oil and dispersant. The Louisiana Bucket Brigade (LABB) was the most active and produced a central mapping resource for spill exposures (Fig. 1). LABB is an environmental justice organization that has worked in the Gulf Coast for ten years to use a technologically-rigged bucket to detect airborne exposures from oil refineries that expose communities living on the "fenceline" of their facilities. These communities are historically Black, and often descendants of former slave communities. They are largely of low socioeconomic status and have little power to respond to the large oil refineries to which they are exposed. LABB trains these communities to capture exposures with the bucket. Samples are then sent to a lab for analysis, and results are often presented to the company in question in order to demand improved protection of local communities (Ottinger 2010). The organization is a historical and contemporary collaborator with other environmental justice groups in the area and plays a key role in framing the debate about local impacts of the oil spill (Rolfes 2010a,b, Weber 2010).
Fig. 1. Comparison of EPA Air Monitoring Sites and LABB Map Reports (Source: LABB 2010)

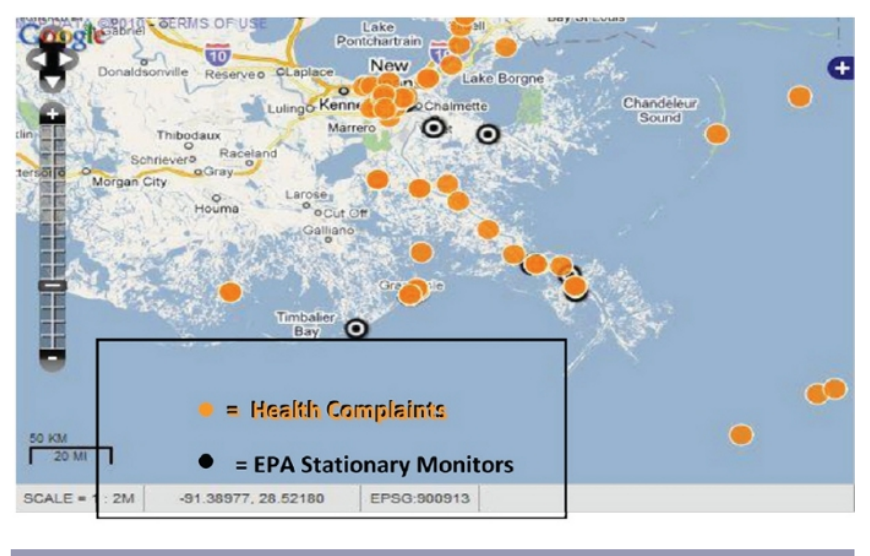

Prior to the spill, LABB staff began to discuss the idea of creating an online platform to collect exposure data. A few weeks before the spill occurred, their site was in place. It was based on an existing interface, called Ushahidi, or 'testimony' in Swahili. Ushahidi is an online, open source mapping system that was used during the Haitian earthquake by several organizations, and has been called the future of disaster response. The Deepwater Horizon spill is its first application in the United States, and to an environmental crisis. The organization that created Ushahidi worked with LABB to create The Oil Spill Crisis Response Map, as a centralized, accessible information database reflecting community experiences and risk perception. (http://www.oilspill. labucketbrigade.org/) This map eventually became the largest and most central repository for citizen science data collection. Citizen science efforts to collect data and map oil spill exposures were conducted by a range of organizations, from the Louisiana Shrimpers Association to SkyTruth, an environmental advocacy organization that maps ecological resources. Many of these samples were not made public, although potentially relevant in lawsuits and for individuals. Much of them were uploaded to the Spill Map. More commonly, however, citizens texted or uploaded information through the online interface about what they saw and smelled in their area. Such crowdsourcing (CS) that allows the public to drive data aggregation is a new form of citizen science, where lay people engage in research design, data collection, and analysis. This crowdsourcing was meant to collect real time exposure data that was otherwise unmeasured. It is the main topic in this research.

\section{CROWDSOURCING AS A NEW FORM OF CITIZEN SCIENCE}

The innovation of citizen science in response to the oil spill and the challenges to its usage can best be explained by situating this project within the broader context of citizen 
science. Citizen science includes approaches where nonexperts are involved in the identification of risks, collection of data, and/or analysis of results (Gibbs 1995). These kind of methods have been used in many past instances of toxic exposures in the United States and internationally. Citizen science is often a form of popular epidemiology people engaging in lay ways of knowing about environmental and technological hazards and then working with professionals to inform environmental health effects. This process has the potential to permanently influence the methods through which research is conducted due to ideas introduced by those usually excluded from the scientific realm (Brown and Mikkelsen 1990).

Lay mapping is one form of popular epidemiology, otherwise called indigenous or public participatory mapping, that has often been used in instances where communities face unmonitored, and often unjust, environmental exposures that go otherwise undetected or dismissed by experts and government officials (Allen 2003, McCormick 2009a). This is a tactical innovation in social movements that helps aggregate community experiences into a form that displays exposures and health outcomes. Haraway (1988) argues that the knowledge represented in this type of science is better informed because it is "....savvy to modes of denial through repression, forgetting, and disappearing acts (178)". She claims that nonexpert inclusion in knowledge production is important because it brings what is lacking into relief.

While citizen science has a long history, online crowdsourcing of disaster effects has only recently become common. On-line information sharing is a growing tool for many types of social actors, and in a range of social processes. Crowdsourcing in the case of the Deepwater Horizon spill transforms lay mapping to an online interface that creates a newly accessible network of knowledge with the potential to shape social relations and risk perceptions by engendering the collectivization of embodied knowledge in affected communities (Corburn 2005). This citizen science has aimed to overcome historical limitations to expert assessments of oil spills by reflecting embodied risk perception of community members and workers (Palinkas et al. 1993b). This fits into the realms of "action oriented," "virtual," and "investigation" forms of citizen science used in other contexts (Wiggins and Crowston 2011). It is different from former types of citizen science used in earthquakes, one of the few disaster contexts in which citizen science has been used, in that data collection is advanced for the purpose of achieving policy and social action. It is also different from many other forms of citizen science that are initiated by experts (Bonney et al. 2009). The Oil Spill Crisis map has been developed entirely separately from scientists and is primarily meant to affect policy, rather than science. However, the Map is similar to other forms of citizen science in that its central task for lay people is the collection of data (CAISE 2009).

\section{DRIVERS OF CITIZEN SCIENCE AND CROWDSOURCING}

Crowdsourcing and citizen-driven data collection is often initiated due to unknown or unassessed risks that lay people see in their day-to-day lives. Assessing risks of the oil spill, or disasters more generally, is a challenge complicated by the "situated" nature of knowledge-generation (Harding 2004) that results in differential perceptions and responses (Clarke and Short 1993, Neil et al. 1994). Characterizing knowledge as "situated" identifies the social position and experiential background as influential in deciding what types of data are important. These processes through which diverse individuals differentially identify risks and exposures are critical in the case of the Deepwater Horizon spill since the identification of risks promises to have massive legal ramifications for fishermen, cleanup workers, local business owners, and many other community members who may be vulnerable to oilrelated exposures. Expert assessments are often limited in their ability to capture the most vulnerable populations that have immediate illness outcomes. Since citizen science is likely to utilize samples that are more representative of day-to-day experiences, even vulnerable populations that have disproportionate exposures or acute reactions can report specialized risks.

Contention has been rife between social actors, some of whom claim that impacts are less than anticipated, while community groups continue to see risks in their daily lives. In this way, the Deepwater Horizon spill is similar to other instances in which discontinuities between lay and expert risk assessments have driven social contention, resulting in emergent lay attempts to assess risk (Sjöberg 1999, McCormick 2009b). Discrepancies between scientific sampling and the informal, daily identification of exposures by lay populations in context are the first, most fundamental problem in detecting health outcomes. While formal risk assessment processes have captured some effects of oil spills, they do not necessarily capture the total range of risks since methods for measurement may be incongruent with the situational specificity of exposures. Lay assessments of risk involve a constant sampling across types of exposures and places in which risks might occur on a day-to-day basis.

There has been little past use of citizen science in the case of oil spills. Communities affected by disasters are more likely to see the sometimes and often radical changes that result from these events. They are, therefore, well-tuned to gather data that is otherwise missed by experts. While citizen science is more expansive that expert approaches, samples taken by lay people may be regarded as ad hoc, inaccurate, and biased. In the case of The Oil Crisis Response Map, citizens collected real time data of a wide range across the Gulf Coast. This is much more comprehensive than most expert-based projects that have taken place, including government-sponsored studies, in that the Map captured air-borne, water-borne, food- 
borne, and other exposures, as well as factors, such as impacts on livelihoods, that could affect mental health. In addition, a much larger number of responses was obtained on the Map than has been collected in expert studies.

\section{SOCIAL CONTEXT AND DISASTERS AS PRETEXT FOR CITIZEN SCIENCE AND CROWDSOURCING}

Crowdsourcing is a new form of lay mapping and citizen science that has the potential for expanding the impact of citizen science by exponentially increasing the number and range of people involved, and it may also be particularly poignant in disaster situations where there is a lack of time and infrastructure for experts to gather data. However, little research has examined the role of citizen science in detecting the health and environmental impacts of disasters. These unique events have particular social contextual dimensions that may shape citizen science. Broadly defined, disasters are nonroutine events in societies or their larger subsystems (e.g., regions and communities) that involve conjunctions of physical conditions with social definitions of human harm and social disruption (Kreps 2001: 3718). Crises emerge when an event that acts as an internal or external trigger generates an urgent threat by undermining not only the coping capacity of existing systems (Boin et al. 2005), but also the public trust in them.

Disasters such as that in the Gulf reveal otherwise disguised social inequalities and problems (Hilgartner and Bosk 1988, Gamson and Modigliani 1989, Clarke 2005). Inequalities between social groups with diverse power relations can be seen in health outcomes of resident populations who are exposed to related risks, and the processes through which their health is assessed. The nongovernmental, governmental and industry institutions and methods available to judge their risk reflect long-held, deeply embedded social norms regarding whose knowledge or concerns are legitimate, whose voices deserve attention, and the social relations between those who guide those decisions and those affected by them. As a result, collecting samples and creating a new body of evidence has been central to many environmental movements (McCormick 2010). Disasters offer an opportunity to shift pre-existing social relations, or continue them as usual. Creating new institutions for citizen science, or recognizing the data and findings engendered on the ground, offers a new form of democracy in a region where legitimate participatory institutions have long been distrusted (Cordasco et al. 2007).

Social context is not only revealed by a disaster, it also shapes response and recovery, including the ways in which citizen science is conducted and put to use. Researchers have long argued that in the phase leading up to a disaster, existing problems often considered systematically normal (Perrow 1984) go unaddressed. Because crises are produced by the normal operation of the nested political, economic, social, and cultural systems, a threat is presented as if it were of sudden origin. However, normalcy often masks system defects and disaster incubation (Turner 1976, Vaughn 1996). Therefore, pre-existing social dynamics continue to reveal themselves within the context of a disaster, or are even exacerbated. For example, communities and first-responders to disasters are key stakeholders in determining resilience, yet they are often entirely marginalized in the processes through which risks and impacts are assessed. In the case of the Gulf, the lack of mechanisms available for citizen reporting of exposures, and the lack of availability of specialized doctors who could address health concerns played into the perceived lack of legitimacy regarding spill impacts.

This process of marginalization shapes responses on the ground. In other cases, such as Fibromyalgia, chronic fatigue syndrome, and chemical sensitivity that have been delegitimized by physicians due to a lack of clear diagnostic criteria, patients experience 'secondary suffering' from the shame and humiliation of having the reality of their experience challenged (Ware 1992). The denial of the patient's experience heightens the possibility of individuals experiencing sustained anxiety and stress about everyday risk (Nettleton 2006). Similar concerns can be manifest in the health-related crises such as past cases of Escherichia coli (Harris 2004), Ebola (Joffe and Haarhoff 2002), Lyme Disease (Aronowitz 1991), and Avian flu (Ozonoff and Pepper 2005), and have affected BP oil spill workers and community members in the Gulf region whose health concerns were dismissed during postdisaster response. Interviewees in this research felt that hearings held by EPA and the National Oceanic Aerospace Administration (NOAA) left their concerns unaddressed. This distrust and feelings of marginalization were a part of what drove the instigation of new methods of data collection and the citizen science used for the oil spill. Spill events, such as this one, are important moments for social change (Kurtz 2004), and in the Gulf of Mexico they are affected by historically contentious and collaborative relationship between communities and the oil industry.

\section{METHODS}

This research is based on qualitative interviews, ethnographic observations, and video data with local social movement organizations, grassroots groups, spill workers, fisherman, local residents, scientists and government representatives were collected in two periods - September, 2010 and September, 2011. The first period was within five months of the spill event, and the second follow up, a year later. Interviewees (31) were identified through a snowball sample that began with local social movement organizations and government officials identified based on documents. Additional interviewees were identified in communities where the highest number of reports to the Crisis Map was made. Interviews were semi-structured and lasted one to two hours. Documents were also collected from government websites and reports. Ethnographic observations were collected during 
collaborations between scientists and fishermen, fishing trips, social movement awareness-raising events, family gatherings by local residents, local cultural events, and a diversity of gatherings in which residents reflected on their experience with spill impacts. Relevant government websites were also analyzed for data regarding risks, and relevant reports were gathered and included in this process. Additional visual data was collected through on-line access to local hearings, dockside chats, and other events where the oil spill was the central topic. Ethnographic data demonstrated the community context in which lay sampling and risk assessment was conducted, while interviews provided a more in-depth picture of the logic that drove such lay engagement.

\section{CROWDSOURCING AS THE NEXT STEP IN LAY MAPPING}

This case demonstrates the facility of crowdsourcing that has not often been the case in lay mapping, simply due to technological and labor constraints. It demonstrates how this new, online, open source approach can result in a wider breadth and larger amount of data that can also be paired with publicly available listings of government monitoring. As such, this case demonstrates how an online system has benefits over traditional paper-based approaches. For example, the LABB mapping system was meant to capture oil spill impacts and exposures in real time. Response categories included a wide variety of spill impacts, including: oil in water, oil on shore, wildlife, odor, health effects, smoke, birds, marine wildlife, livelihood threatened, property damaged by oil, solutions and ideas, community meetings and organizing, needs, cultural loss, tainted seafood, dispersant in use, and sampling results. In past cases of lay mapping, capturing this amount and diversity of data has been limited by technical capacity.

The Map also captured many more reports than lay mapping efforts have in the past. For example, breast cancer advocates in Long Island gathered hundreds of responses to a door-todoor survey about incidence (McCormick et al. 2003), which is similar to other maps that have been localized in a fairly circumscribed community. The Crisis Map has been widely populated across the region. By December 1, 2010, reports had been received from Texas, Louisiana, Mississippi, Alabama and Florida, as well as from Mexico, Cuba, and the Cayman Islands. The majority of them were in Southern Louisiana, in Terrebonne and Lafourche Parishes. An analysis of the response map conducted by the Brigade found that by October 10, there were 2,628 reports to the map (Louisiana Bucket Brigade 2010).

The open source coding of the map made it easier for LABB to compare its results with those of government sources, therefore adding another layer of power. The majority of reports on the Map were about oil on water, followed by oil on shore, odor, and health effects. In the report, EPA's air monitoring sites were overlaid with reports regarding odors and health complaints. This showed how there were many reports in places where no air monitors existed.

\section{CROWDSOURCING IN THE CONTEXT OF EXPERT ASSESSMENTS}

Crowdsourcing (CS) was the new approach to data collection and disaster response that social movements used in the BP spill. The CS of citizen science efforts involved lay mapping and collecting multiple types of samples, including air, water, sediment, and seafood. While it is difficult to explicitly assess the differences between data collection in the case of the Oil Spill Crisis Response Map and other expert-based approaches, the crowdsourcing approach introduced by LABB in order to assess risk and exposure has the potential to address past research gaps and public controversy regarding disasters (Backstrand 2002, Edwards and von Winterfeldt 2003). The information gathered in this crowdsourcing tool reflects experiences otherwise unaddressed in expert risk assessment methods, as is often true when lay people collect information about risks in their own lives (Brown 1992). Traditionally, there has been limited citizen science that challenges expert knowledge of disaster risks. This situation is changing with the Deepwater Horizon spill and implementation of Ushahidi.

The LABB approach overlapped with some expert and government risk assessments, but expanded upon them by creating space for lay measures of traditional expert categories. For example, NOAA measures different categories - marine transport and shipping fairways - and similar impacts in the form of oil impacted offshore habitats and sea life. The EPA was responsible for measuring some related exposures on land, such as air borne contaminants. The National Institute of Occupational Health and Safety (NIOSH) and the Occupational Health and Safety Administration (OSHA) were responsible for assessing exposures for workers, including air borne contaminants on clean-up boats. Most human health assessments have found little threat to human populations, including workers, local communities, or those who consume seafood. For instance, air monitoring by the Environmental Protection Agency http://www.epa.gov/bpspill/air-mon.html during the period of the active spill found only a handful of days where airborne exposures were above safe levels. The sites of air monitors also influenced these findings. They may have been more distant from exposures than many human populations. In August, the National Institute for Occupational Safety and Health (NIOSH) released an interim report that emphasized the risks to oil workers due to heat stress, while minimizing that $46 \%$ of respondents also had a rash and other neurological symptoms (NIOSH 2010).

Although these official monitoring processes and reports demonstrate minimal concern regarding human health risks, local groups have continued to be concerned about such threats. Therefore, this analysis demonstrates two, interlocking issues that are difficult to disentangle. First, it 
shows that residents noticed exposures, such as smells, smoke, and other potential risk factors, that were not detected at harmful levels by expert risk assessors. Therefore, crowdsourcing detected factors that were not found in federal assessments. This relates to the second issue, that it is possible, but not provable, that crowdsourcing is able to detect exposures that expert assessors do not. While the first issue relates to the perception of risks that remained heightened for those participating in mapping reports, the second informs whether or not crowdsourcing can better detect actual exposures. Comparing these two types of reports shows that concerns are sustained even in light of expert assessments, but cannot result in the claim that one type of assessment is actually more effective in capturing exposures than the other.

\section{LAY EVIDENCE IN ASSESSING LONG-TERM IMPACTS}

In the past, citizen science has had important ramifications for the understanding of health effects. For example, in the case of Love Canal, one of the most well-known cases of community-level contamination in the United States that took place in New York State, local homeowners developed their own map of birth defects and illnesses in order to show the effects of toxics buried under their community (Blum 2011). While their map was dismissed as unscientific as has often been the case in lay mapping (McCormick 2009b), it did motivate the implementation of a study by EPA that eventually resulted in the reimbursement of community members for the loss of their homes. When LABB first reported the results of its mapping efforts, it received massive media attention across the country. The New York Times, National Public Radio, local papers, and many others publicized the data that LABB had been collecting and the innovative strategy the organization was using. This attention resulted in some consideration of the LABB findings in federal-level proceedings. The Director of the organization, Anne Rolfes, testified before the House Natural Resources Subcommittee on Insular Affairs, Oceans and Wildlife on June 10, 2010. In this phase of the disaster response, she focused on information control by BP, a lack of commitment to pay workers in that area to clean-up the spill, the need for improved health services. For example, she stated a series of counts from the Spill Map: Odor Complaints- 181, Health Complaints from Exposure- 86, Oil on Marine Wildlife- 63, Oil on Birds- 47, Oil on Other Wildlife- 49, Oil on Shore- 130, and Oil on Water- 111 (Rolfes 2010a). These counts were derived from the Spill map and used to show that $\mathrm{BP}$ was not openly showing data regarding risks with the public.

In her second testimony to the Senate Committee Subcommittee on Commerce, Justice, Science and Related Agencies in July, 2010, Rolfes pointed to the deficient capacity of EPA and NOAA to be able to sufficiently sample the air and water quality in order to be able to capture the exposures that were already being entered into the oil spill map. She related one example that was uploaded to the site. This is an excerpt from the report:

My 3-year-old son was diagnosed with pneumonia
on Mondaymorning. He was admitted to the hospital
Monday afternoon and finally discharged
Wednesday afternoon. He was a perfectly healthy
and happy 3-year-old boy until this incident. I read
that children have been susceptible to dispersant-
related pneumonia. If this is true, I have a feeling
that this was his problem, as he has had no
significant health problems up to this point. He was
in the hospital for three days, with the fourth day at
home. I was, of course, by his side the entire time.
Due to my being there with my son, I had to miss
nearly a week of work (Rolfes $2010 b$ ).

In this way, $\mathrm{LABB}$ was able to introduce the exposures felt by those in communities into federal policy circles and submit legally-recorded evidence. While this was definitively not the first time that regulators and agencies had heard personal testimonies (as they did when public meetings were held across the Gulf Coast), it provided a space in which LABB could demonstrate the accumulated community-level knowledge of health effects and dissatisfaction with government responses that were occurring across the Gulf. This type of accumulated knowledge has been used effectively in many environmental struggles, and in this case, the crowdsourced nature of the data provided a much broader swath of information that leant increased credibility to LABB.

The month after Rolfes' second testimony, the National Institutes of Health announced the planning of a \$10 million budget for The Gulf Long Term Follow-Up Study (GuLF Study), and an additional \$10 million from BP to supplement this project. The funding from BP is being administered through the Gulf of Mexico Research Initiative (GRI), a tenyear, \$500 million independent research program established by BP to assess the impacts of the spill. The GuLF study is surveying 55,000 workers on the oil spill regarding health outcomes, comparing these respondents to nonworkers. The study is intramural and is therefore designed by researchers at $\mathrm{NIH}$ or the National Institute of Environmental Health Sciences (NIEHS) and other agency representatives, yet the study planners announced their intent to gather community input in planning. Sandler, the Director of the GuLF Study, said: that her team would 'love to be able to take advantage of' any existing data collected by local nonprofits (Schor 2010), such as LABB. However, the Institute had already decided on a number of aspects of the study before beginning to consult with the community. First, the main areas of interest were respiratory, cardiovascular, hematologic, mental health, cancer, neurologic, liver, immunologic, renal, dermatologic, and reproductive effects. Second, the study groups would fall into two separate categories, an active cohort of 20,000 
workers and 5,000 controls that would be actively followed throughout a long-term study, and a passive cohort, to be tracked by record linkage on vital statistics and cancer registries.

The leaders of this study admit there are some limitations to its outcomes, including an inability to correlate any exposure to the spill with specific health outcomes (Reardon 2011). This limitation results from a lack of baseline data to which later exposures can be compared. The most up-to-date information will be collected as a part of the study, but much after the spill took place. In addition, the study may be able to use some of the air and seafood monitoring offered by other agencies, but connecting those macro-level data to individual exposures is not promised. There are many other sources of similar exposures in the Gulf region to which the outcomes of the study can be attributed. As a result, local citizen efforts represent some of the little evidence available to determine effects. This study is unlikely to include real time monitoring data from the citizen science efforts, despite the need for similar information. As such, there limitations to expert-driven study being informed by evidence collected by LABB and other organizations. In this sense, both expert assessments and crowdsourcing have limitations whose intersection might be beneficial to both, if planned and managed appropriately.

The social context previous to the spill also affected crowdsourcing efforts, and may shape future citizen science that measures oil-related exposures. LABB's process of mapping was hindered by their historical involvement focused primarily on fenceline communities who were largely unaffected by the oil spill. The organization was forced to expand its collaboration with fishermen, workers, and other citizens in the southern Louisiana Bayou deeply involved in the seafood industry, which has been deeply depressed by the oil spill, and the oil industry. LABB worked with local fishermen to identify areas they were most concerned about, and helped connect them with scientists who took additional samples to measure spill effects. Others conducted their own sampling of seafood and other materials without engaging with LABB, resulting in some disjointed citizen science efforts rather than a larger sense of social cohesion as often occurs in movements using citizen science (McCormick 2009b).

\section{CONCLUSIONS}

There is an emerging role for crowdsourcing as a form of citizen science. These findings show that crowdsourcing is key to this new realm of citizen science that represents a transition from lay mapping, which has been a common tactic in the environmental movement for over two decades, to an online data gathering system that allows a broader range of participation, a larger amount of more diverse data that potentially represent a broader range of impacts, and the facility of comparing citizen reports with government monitoring, therefore increasing the ability of advocates to show its value.
There is a difference between citizen and expert assessments, including the high-level government response to crowdsourcing. The conduct of citizen science affects the dynamics of social movements and civil society. It may also shape the conduct of political decision-making and/or the development of expert science. By seeing innovations in movements wherein civil society controls the process of surveying and data collection, this research seeks to contribute to an understanding of how technology is used in social movements (Hess 2005), and the role of technology in governance (Jasanoff 2004). As such, this research highlights the need to take an alternative approach to that traditionally adopted in surveillance studies where expert codifications of risk control the behaviors and outcomes of those being surveyed (Hacking 1999).

While it is difficult to specifically outline the policy impacts of any social movement. Further research on this event and others can help facilitate the understanding of crowdsourcing impacts, limitations and strengths. These next steps in disaster research are important because they may offer improved understanding of how crowdsourcing can catalyze resilience on multiple fronts.

Responses to this article can be read online at: http://www.ecologyandsociety.org/issues/responses. php/5263

\section{Acknowledgments:}

This material is based upon work supported by the National Science Foundation under Grant No. 08-553. The author would like to thank the Louisiana Bucket Brigade for their help, and two anonymous reviewers for their extensive feedback.

\section{LITERATURE CITED}

Allen, B. 2003. Uneasy Alchemy: Citizens and Experts in Louisiana's Chemical Corridor Disputes. MIT Press. Cambridge, MA. U.S.A.

Arata, C. M., J. S. Picou, G. D. Johnson, and T. S. McNally. 2000. Coping with technological disaster: an application of the conservation of resources model to the Exxon Valdez Oil Spill. Journal of Traumatic Stress 13: 23-39.

Aronowitz, R. A. 1991. Lyme disease: the social construction of a new disease and its social consequences. The Milbank Quarterly 69(1): 79-112. http://dx.doi.org/10.2307/3350122

Backstrand, K. 2002. Civic science for sustainability: reframing the role of experts, policy-makers and citizens in environmental governance. Global Environmental Governance 3(4): 24-41. http://dx.doi.org/10.1162/152638003322757916 
Blum, E. D. 2011. Love Canal Revisited: Race, Class, and Gender in Environmental Activism. University of Kansas Press. Wichita, KS. USA.

Boin, A., P. Hart, E. Stern and B. Sundelius. 2005. The Politics of Crisis Management: Public Leadership under Pressure. Cambridge University Press. Cambridge, U.K. http://dx.doi. org/10.1017/CBO9780511490880

Bonney, R., C. Cooper, J. Dickinson, S. Kelling, T. Phillips, K. Rosenberg, and J. Shirk. 2009. Citizen science: a developing tool for expanding science knowledge and scientific literacy. BioScience 59(11):977-984. http://dx.doi. org/10.1525/bio.2009.59.11.9

Brown, P. 1992. Popular epidemiology and toxic waste contamination: lay and professional ways of knowing. Journal of Health and Social Behavior 33: 267-281. http://dx.doi. org $/ 10.2307 / 2137356$

Brown, P. and E. J. Mikkelsen. 1990. No Safe Place: Toxic Waste, Leukemia and Community Action. University of California Press, California, USA.

Center for Advancement of Informal Science Education (CAISE). 2009. Public Participation in Scientific Research: Defining the Field and Exploring Its Potential for Informal Science Education. Center for Advancement of Informal Science Education. Washington, DC. U.S.A.

Clarke, L. and J. F. Short, Jr. 1993. Social organization and risk: some current controversies. Annual Review of Sociology 19: 375-399. http://dx.doi.org/10.1146/annurev.so.19.080193.002111

Clarke, L. 2005. Worst Cases: Terror and Catastrophe in the Popular Imagination. University of Chicago Press. Chicago, IL. U.S.A.

Corburn, Jason. 2005. Street Science: Community Knowledge and Environmental Health Justice. MIT Press, Cambridge, MA, USA.

Cordasco, K., D. P. Eisenman, D. C. Glik, J. F. Golden, and S. M. Asch. 2007. "They blew the levee": distrust of authorities among Hurricane Katrina evacuees. Journal of Health Care for the Poor and Underserved 18(2): 277-282. http://dx.doi. org/10.1353/hpu.2007.0028

Dan, A., R. Ramakrishnan, and A.Y. Halevy. 2011. Crowdsourcing systems on the world-wide web. Communications of the ACM 54: 88-98. http://dx.doi. org/10.1145/1924421.1924442

Edwards, W. and D. von Winterfeldt. 2003. Public values in risk debates. Risk Analysis 7(2): 141-158. http://dx.doi. org/10.1111/j.1539-6924.1987.tb00979.x

Environmental Protection Agency. 2012. Monitoring air quality along the Gulf Coast. [online] URL: http://www.epa. gov/bpspill/air-mon.html\#how
Forbes, G. L. 1994. The Braer Oil Spill Incident - Shetland, January 1993. International Journal of Environmental Health Research 4(1): 48-59. http://dx.doi.org/10.1080/09603129409356797

Gamson, W. and A. Modigliani. 1989. Media discourse and public opinion on nuclear power: a constructionist approach. The American Journal of Sociology 95(1): 1-37. http://dx.doi. org/10.1086/229213

Gibbs, L. 1995. Dying from Dioxin: A Citizen's Guide to Reclaiming Our Health and Rebuilding Democracy. South End Press. Boston, MA. USA.

Golet, G. H., P. E. Seiser, A. D. McGuire, D. D. Roby, J. B. Fischer, K. J. Kuletz, D. B. Irons, T. A. Dean, S. C. Jewett, and S. H. Newman. 2002. Long-term direct and indirect effects of the 'Exxon Valdez' oil spill on pigeon guillemots in Prince William Sound, Alaska. Marine Ecology Progress Series 241: 287-304. http://dx.doi.org/10.3354/meps241287

Ha, M., W. J. Lee, S. Lee, and H. Cheong. 2008. A literature review on health effects of exposure to oil spill. Journal of Preventive Medicine and Public Health 41(5):345-35. http:// dx.doi.org/10.3961/jpmph.2008.41.5.345

Hacking, I. 1999. Making up people. Pp. 161-171 in M. Biagioli, editor. The Science Studies Reader. Routledge. New York NY. U.S.A.

Haraway, D. 1988. Situated knowledges: the science question in feminism and the privilege of partial perspective. Feminist Studies 14: 575-599. http://dx.doi.org/10.2307/3178066

Harris, A. S. 2004. A Socio-ecological autopsy of the E. coli O157:H47 outbreak in Walkerton, Ontario, Canada. Social Science \& Medicine 58: 2601-2612. http://dx.doi. org/10.1016/j.socscimed.2003.09.013

Hess, D. J. 2005. Technology- and product-oriented movements: approximating social movement studies and science and technology studies. Science, Technology \& Human Values 30(4): 515-535. http://dx.doi.org/10.1177/0162243905276499

Hilgartner, S. L. and C. Bosk. 1988. The rise and fall of social problems: a public arenas model. The American Journal of Sociology 94(1): 53-78. http://dx.doi.org/10.1086/228951

Hoch, M. 2010. New Estimate Puts Gulf Oil Leak at 205 Million Gallons. PBS NewsHour MacNeil/Lehrer Productions. [online] URL: http://www.pbs.org/newshour/rundown/2010/08/ new-estimate-puts-oil-leak-at-49-million-barrels.html [accessed June 1, 2011].

Jasanoff, S. 2004. States of Knowledge: The Co-Production of Science and Social Order. Routledge. New York, NY, USA.

Joffe, H. and G. Haarhoff. 2002. Representations of far-flung illnesses: the case of Ebola in Britain. Social Science and 
Medicine 54(6): 955-969. http://dx.doi.org/10.1016/S0277-9536 (01)00068-5

Kreps, G. A. 2001. Sociology of disaster. in N. J. Smelser and P. B. Bates, editors. International Encyclopedia of the Social and Behavioral Sciences Pages 3718-3721. Elsevier Publishers. Amsterdam, The Netherlands. http://dx.doi. org/10.1016/B0-08-043076-7/01866-0

Kujawinski, E., M. C. Kido Soule, D. L. Valentine, A. K. Boysen, K. Longnecker, and M. C. Redmond. 2011. Fate of dispersants associated with the Deepwater Horizon Oil Spill. Environment, Science and Technology. 45(4): 1298-1306. http://dx.doi.org/10.1021/es103838p

Kurtz, R. S. 2004. Coastal oil pollution: spills, crisis, and policy change. Review of Policy Research 21(2): 201-219. http://dx.doi.org/10.1111/j.1541-1338.2004.00069.x

Louisiana Bucket Brigade. 2010. Oil Spill Crisis Map: Initial Analysis and Review. New Orleans, Louisiana, USA. [online] URL: http://www.law.tulane.edu/uploadedFiles/News/News Items/ Current year/Oil Spill_Crisis Map Initial Analysis and Review. pdf.

Lyons, R. A., J. M. Temple, D. Evans, D. L. Fone, and S. R. Palmer. 1999. Acute health effects of the Sea Empress oil spill. Journal of Epidemiology and Community Health 53: 306-310. http://dx.doi.org/10.1136/jech.53.5.306

Markowitz, G. and D. Rosner. 2003. Deceit and Denial: The Deadly Politics of Industrial Pollution. University of California Press. Berkeley, CA. U.S.A.

McCormick, S. 2009a. Democratizing science movements: a new framework for contestation. Social Studies of Science 37: 609-623. http://dx.doi.org/10.1177/0306312707076598

McCormick, S. 2009b. Mobilizing science: movements, participation and the re-making of knowledge. Temple University Press. Philadelphia, PA. U.S.A.

McCormick, S., P. Brown, and S. Zavestovski. 2003. The personal is scientific, the scientific is political: the environmental breast cancer movement. Sociological Forum 18: 545-576. http://dx.doi.org/10.1023/B:SOFO.0000003003.00251.2f

Morita, A., Y. Kusakaa, Y. Deguchia, A. Moriuchib, Y. Nakanagab, M. Ikic, S. Miyazakid, K. Kawaharae. 1999. Acute health problems among the people engaged in the cleanup of the Nakhodka oil spill. Environmental Research 81 (3): 185-194. http://dx.doi.org/10.1006/enrs.1999.3979

Neil, N, T. Malmfors, and P. Slovic. 1994. Intuitive toxicology: expert and lay judgments of chemical risks. Toxicological Pathology 22(2): 198-201. http://dx.doi. org/10.1177/019262339402200214

Nettleton, S. 2006. 'I just want permission to be ill': Towards a sociology of medically unexplained symptoms. Social
Science and Medicine 62(5): 1167-1178. http://dx.doi. org/10.1016/j.socscimed.2005.07.030

Ottinger, G. 2010. Buckets of resistance: standards and the effectiveness of citizen science. Science, Technology \& Human Values 35 (2): 244-270. http://dx.doi.org/10.1177/01$\underline{62243909337121}$

Ozonoff, D., and L. Pepper. 2005. Ticket to ride: spreading germs a mile high. The Lancet 365(9463) 12: 917-919. http:// dx.doi.org/10.1016/S0140-6736(05)71058-8

Paine, R. T., J. L. Ruesink, A. Sun, E. L. Soulanille, M. J. Wonham, C. D. G Harley, D. R. Brumbaugh, and D. L. Secord. 1996. The Exxon Valdez spill and Its aftermath. Annual Review of Ecology and Sytematics 27: 197-235. http://dx.doi. org/10.1146/annurev.ecolsys.27.1.197

Palinkas, L. A., J. S. Petterson, J. Russell, and M. A. Downs. 1993a. Community patterns of psychiatric disoders after the Exxon Valdez oil spill. American Journal of Psychiatry 150 (10): 1517-1523.

Palinkas, L. A., M. A. Downs, J. S. Petterson, and J. Russell. 1993b. Social, cultural, and psychological impacts of the Exxon Valdez oil spill. Human Organization 52(1): 1-13.

Perrow, C. 1984. Normal Accidents: Living with High Risk Technologies. Basic Books. New York, NY. U.S.A,

Picou, J. S., B. K. Marshall and D. A. Gill. 2004. Disaster, litigation, and the corrosive community. Social Forces 82(4): 1493-1522. http://dx.doi.org/10.1353/sof.2004.0091

Reardon, S. 2011. NIH begins study of oil spill's Impact on Residents. Science Magazine 28 February 2011. [online] URL:http://news.sciencemag.org/scienceinsider/2011/02/nihbegins-study-of-oil-spills.html.

Rolfes, A. A., 2010a. (Director, Louisiana Bucket Brigade) 2010a. Testimony on FY10, House Natural Resources Subcommittee on Insular Affairs, Oceans and Wildlife (Date: 5/10/10). Text from: 111th Congress Hearing Archives. [online] URL: http://naturalresources.house.gov/calendar/ eventsingle.aspx? EventID=186200. Accessed 11/5/11

Rolfes, A.A., 2010b. (Director, Louisiana Bucket Brigade) 2010b. Testimony on FY10, Senate Committee Subcommittee on Commerce, Justice, Science and Related Agencies (Date: 7/15/10). Text from: Government Printing Office. [online] URL: http://www.gpo.gov/fdsys/pkg/CHRG-111shrg63179/ html/CHRG-111shrg63179.htm. Accessed 12/1/11

Sabucedo, J. M., C. Arce, C. Senra, G. Seoane, and I. Vázquez. 2010. Symptomatic profile and health-related quality of life of persons affected by the Prestige catastrophe. Disasters 34 (3): 809-820. http://dx.doi.org/10.1111/j.1467-7717.2010.01170. $\underline{\mathrm{X}}$

Schor, E. 2010. Locals Track Gulf Oil Spill's Health Impacts, Paving Way for Federal Study. The New York Times. [online] 
URL:http://www.nytimes.com/gwire/2010/08/19/19greenwirelocals-track-gulf-oil-spills-health-impacts-pa-41267.html.

Sjöberg, L. 1999. A dilemma in risk management. Human Ecology Review 6(2): 1-9.

Trumbull, D. J., R. Bonney, D. Bascom, and A. Cabral. 2000. Thinking scientifically during participation in a citizenscience project 84(2): 265-275.

Turner, B. A. 1976. The organizational and interorganizational development of disasters. Administrative Science Quarterly 21(3): 378-397. http://dx.doi.org/10.2307/2391850

Vaughn, D. 1996. The Challenger Launch Decision: Risky Technology, Culture, and Deviance at NASA. University of Chicago Press. Chicago, IL. U.S.A.

Weber, S. 2010. Crowdsourcing the Gulf oil spill. Public Television. [online] URL: http://www.pbs.org/wnet/need-toknow/environment/crowdsourcing-the-gulf-oil-spill/459/

Ware, N.C. 1992. Suffering and the Social Construction of Illness: The Deligitimation of Illness Experience in Chronic Fatigue Syndrome. Medical Anthropology Quarterly 6: 347-361. http://dx.doi.org/10.1525/maq.1992.6.4.02a00030

Wiggins, A., and K. Crowston. 2011. From Conservation to Crowdsourcing: a typology of citizen science. in pp. 1-10 44th Hawaii International Conference on System Sciences. Hawaii International Conference on System Sciences (HICSS 2011), IEEE. doi:10.1109/HICSS.2011.207 http://dx.doi.org/10.1109/ HICSS.2011.207 